\title{
Viagem, poesia e morte em Age de Carvalho
}

Travel, poetry and death in Age de Carvalho

\author{
Mayara Ribeiro GUIMARÃES ${ }^{1}$ \\ Universidade Federal do Pará (UFPA)
}

\begin{abstract}
RESUMO: Análise dos poemas "Atravessando" e "Ele, o rico-de-sombras", de Age de Carvalho (Ainda: em viagem, 2015), sob a perspectiva do topos da viagem como experiêncialimite ligada à morte e à natureza da linguagem poética. A partir da reflexão em torno da figura de Odisseu enquanto signo literário que surge na Odisseia, de Homero, e se abre aos sistemas de signos que cada período literário lhe conferirá, pela perspectiva do crítico italiano Piero Boitani, busca-se discutir a trágica verdade que acompanha a poesia: a de que conhecer é perecer, e que o fenômeno poético se manifesta como ponto frágil entre duas margens.
\end{abstract}

PALAVRAS-CHAVE: Age de Carvalho, viagem, poesia brasileira contemporânea, Odisseu.

ABSTRACT: Analysis of two poems by Age de Carvalho (in Ainda: em viagem, 2015): "Atravessando" and "Ele, o rico-de-sombras", under the light of the topos of travel as an experience of being in the threshold of two different worlds, and how it connects to the experience of death ando f wrting poetry. The aim is to discuss the tragic truth that inhabits poetry: that knowing is perishing and that the poetic phenomenon manifests itself as a fragile threshold between two borders. The paper will also pass through the representation of Odysseus as a literary sign that emerges in Homer's Odyssey and opens up to the systems of signs that each literary period will confer on him, from the perspective of the Italian critic Piero Boitani.

KEYWORDS: Age de Carvalho, travel, contemporary Brazilian poetry, Odysseus.

“Conciso, limpo de aparas e redundâncias, [Caveira 41] pareceu-me exemplo para o que se pode fazer hoje no Brasil em matéria de renovação da linguagem poética". Assim se expressou o poeta e crítico Affonso Ávila a propósito da leitura de Caveira 41, sexto livro de poemas Age de Carvalho, em carta enviada em agosto de 2003. Com essa frase situou a poesia de Age como referência de renovação na geração de escritores contemporâneos a que pertence.

\footnotetext{
${ }^{1}$ Professora de Literatura Brasileira na Universidade Federal do Pará, Belém e doutora em Literatura Brasileira pela Universidade Federal do Rio de Janeiro. E-mail: mayribeiro@uol.com.br
} 
Possivelmente o livro mais bem acabado de toda a sua trajetória, e o favorito do amigo Max Martins, a sobriedade, a "postura severa da frase", a "não concessão ao sentimental vago e fugidio" são outros atributos destacados por Ávila na mesma carta e que fazem de sua poesia um "rigoroso instrumento" de "profundidade de pensamento", ao contrário do suposto hermetismo que lhe é atribuído. Admirador de Drummond e de Guimarães Rosa, a quem sempre retorna em leitura, Age desenvolveu uma poesia de alta carga lírica, condensação na concretude e justaposição de imagens, com alto teor filosófico e reflexivo.

É assim que a viagem, que confere título ao seu mais recente livro, Ainda: em viagem, ganha forma como topos poético de experiências-limite em alguns de seus livros, entre eles Caveira 41 e Trans. Escrever é falar de dentro de um lugar de existência e desaparecimento, fazendo coexistir uma zona umbrática que ultrapassa as peras, os limites que dão forma às coisas, ao indivíduo e ao mundo, em direção a uma queda, uma treva, ainda que simbólica. O primeiro personagem da literatura ocidental a cruzar essa margem é Odisseu, não por acaso também aquele a encenar a primeira grande viagem da tradição ocidental e que se converte, com o passar dos séculos, em uma sombra literária, absorvida e transformada pelas diferentes épocas, segundo seus traços culturais e históricos.

A experiência de escrita engendrada na Odisseia está profundamente ligada a uma vivência de morte que a narrativa dos feitos de Odisseu, cantada pelo herói na corte do rei Alcínoo, inaugura. Ali, o personagem assume, entre tantas funções desempenhadas ao longo da narrativa, a de aedo, quando convidado a revelar sua história diante dos feácios. E o que canta é o relato de um naufrágio e de uma descida ao reino dos mortos, de onde se aprende que é necessário morrer para poder narrar, para fazer surgir a poesia. Do canto IX ao canto XII da Odisseia, o herói dá forma ao relato que funda o mito no instante em que a narração acontece, transformando o caminhar para a morte em poesia. No percurso da exploração da vida e do conhecimento, é necessária a experiência do limite. Como fazer falar essa experiência? Como dizer de dentro dela? Dessa solidão última e profunda, o ser solto no oco do universo, sua forma desaparecendo?

Diante disso, proponho a leitura de nosso topos como abertura a um avançar para o fim e para a perda. Porque poesia e morte aparecem dentro da tradição literária ocidental como experiências que se cruzam e sobrepõem. Se nesta narrativa inaugural, fundadora da tradição literária do ocidente, a poesia nasce como mito, na modernidade 
ela retorna como reescrita, erguendo-se como memória de si e do mundo, do conhecimento individual e coletivo. Entretanto, o vestígio da figura de Odisseu permanece nos séculos seguintes até os dias de hoje ecoando uma trágica verdade: de que "conhecer é também perecer". Essa a tragédia da linguagem. Porque a viagem interna e para fora de si se dá pela linguagem. E a poesia, ponto frágil entre duas margens, é sempre uma tentativa de exprimir o indizível. A linguagem, diz Blanchot, "deve seu sentido não ao que existe, mas ao seu recuo diante da existência" (BLANCHOT, p. 312), a esse afastamento, a essa interdição do toque, da visão. Como se a poesia fosse o reconhecimento de algo fugidio que desaparece no mesmo instante em que aparece ao olhar, e que vige justamente nessa dinâmica de interdição, e que por isso queima.

E talvez aí a poesia de Drummond e a narrativa de Guimarães Rosa digam tanto a Age de Carvalho, nessa observação silenciosa do mundo e suas situações corriqueiras do cotidiano, a que é atribuída dimensão existencial, na diligência de interpretar a condição de estar no mundo. Em sua falta de recursos para dominar o fỉm, o homem dirige-se ao momento de aniquilamento, em dignidade, e escreve. "Acordo para a morte" (DRUMMOND, p. 176) diz o poema que perfaz o périplo do sujeito entre a manhã e a noite pela cidade, como metáfora da jornada humana pelo mundo. "É o sol. Os bondes cheios. O trabalho./Estou na cidade grande e sou um homem na engrenagem./Tenho pressa. Vou morrer" (DRUMMOND, p. 177). A condição ambígua do homem, de saber-se ao mesmo tempo sujeito e objeto de uma escolha, negociando com a morte, atrasando esse termo, força-o a tornar-se senhor de sua Hora. É assim, portanto, que morte e viagem convertem-se em caminhos para a poesia.

Odisseu é ao mesmo tempo antigo e moderno. Atravessa os séculos e vira signo. Cada vez que segue em uma viagem, transforma-se e assume vários nomes. Cada cultura e época vai interpretá-lo com seus sistemas de signos e assim lhe é atribuída uma dupla valência: a do personagem grego e a dos horizontes abertos por cada civilização. Odisseu constitui, portanto, uma forma multiforme, cheia de potencialidades, paradigma do conhecimento de si e do mundo na dor, para Homero, mas também da consciência do fim, como propõe Piero Boitani em A sombra de Ulisses (2005).

Uma das maneiras que Age de Carvalho encontra para operar a relação entre poesia, morte e viagem passa, por exemplo, pelas noções de tempo e espaço engendradas pela torção e fragmentação sintática. Poemas dedicados ao Ano Novo, 
limiar entre dois ciclos, entre um tempo e estado de ser que já não existem, atualizam esse vínculo. É o caso do poema "Em viagem", em torno da imagem da errância, do "estado, de estar/em-viagem", dando notícias da condição do ser, sozinho, exilado de si mesmo, apátrida, na "Exlândia" do desterro individual. Errar repetidamente o território, distante da ex-terra, um dia pátria, traduz também o exercício de escrita e de estar em casa e em deslocamento permanentemente. De dentro do estado de travessia emerge o seu território - Apátria, Exlândia, Desterra, mais concreto e possível porque território da linguagem.

Pensando nessa condição de errância, tão colada à figura do viajante, deslocado entre mundos distintos, este tema aparece de forma direta em poemas que realçam esse estado, mas também indiretamente, desdobrando-se em matérias a ele associadas: o nascimento, o exílio, a metamorfose, a ancestralidade, o estar-no-mundo. Como dito antes, o primeiro viajante na literatura do Ocidente remete à Grécia arcaica e a Homero, especificamente, e estas referências, junto a Safo, Heráclito e Catulo erguem na poesia de Age de Carvalho uma ponte entre o mundo antigo e o moderno (ao gosto de um Mário Faustino, poeta de sua predileção). Nesse universo estão também referências à Divina Comédia e à figura emblemática de Cristo.

Com eles, Age se arma de um referencial que permite articular contrastes altamente líricos, justapondo a linguagem que descreve o acontecimento trivial com a transmissão inexplicável do inefável, logrando status de ordinário ao que se manifesta como extraordinário. Sua poesia estabelece uma ligação do sagrado com as atividades mais prosaicas, de modo que ambas dividem o mesmo lugar de expressão da vida. $\mathrm{O}$ inefável é entendido aqui como mergulho no âmago da existência e a poesia como uma experiência de conhecimento e reconhecimento de algo incomunicável, mas que se insiste em dizer, em seu poder de nomear o que excede o dizível e a compreensão. Penso que isso traduza bem sua crença na poesia, essa casa do ser, reduto de salvação do homem descrente e errante, única saída possível para atrasar o término.

Parto, portanto, de duas imagens literárias que atravessam essa tradição e chegam em nosso tempo, duas sombras que pairam sobre a cultura ocidental, para com elas discutir o inesgotável laço entre poesia e morte e como ele se ata ao topos proposto na poética de Age. Porque a viagem constitui o indivíduo e indica o transitório, o movente, a formatividade do indivíduo, seja ela externa ou interna. Se externa, por territórios desconhecidos e culturas distintas, em forma de exílio ou em busca de conhecimento e contato com o novo. Se interna, pelo tempo e como experiência 
gnosiológica. A exterioridade da paisagem, a forma das línguas, a espontaneidade do cotidiano levando à interioridade da alma. Essas são relações que unem as figuras do estrangeiro, do poeta e do tradutor em torno da ideia do "fora de lugar" ou do não-lugar, e de estados de liminaridade ${ }^{1}$, pensando o poeta como aquele que está em sua própria língua como um estrangeiro ${ }^{2}$. Em torno também da condição permanente e temporária de uma busca, por vezes frustrada, mas sempre condicionante do movimento, de territórios e raízes.

O percurso de Odisseu ao reino dos mortos (Hades), seguido da nekya (evocação dos mortos) e sua conexão com o episódio das Sereias, são uma sombra na literatura do Ocidente, arco que se distenderá por muitos séculos até chegar aos tempos de hoje. Nela, Tirésias profetiza uma última viagem, depois do retorno para casa, a um lugar que não conhece os navios e a comida com sal. Essa profecia, como propõe Boitani, prefigurada no canto IX, registra uma abertura para o futuro, no horizonte cultural, estético, histórico e ontológico, ao mesmo tempo em que já está condenada a existir como outra coisa, a ter outro significado, condenada ao "outro". Nesta descida aos infernos, Odisseu faz uma incursão "per umbram ad umbras" (pela sombra até a sombra), isto é, pelo desconhecido, na fronteira entre o vivo e o não-vivo, tornando-se um ser da morte ou um ser-em-morte, ultrapassando "o limite (peras) atribuído ao homem" (cf. BOITANI, 2005, p. 3). Se, de um lado, o texto coloca em contato as dimensões do ser e do não-ser, de outro, a profecia prevê um Odisseu apagado pelo anonimato, abandonada sua história pessoal, exaltado agora como viajante anônimo, como será posteriormente confirmado por Dante.

A segunda é justamente o relato da última jornada de Ulisses, detalhada pela sombra do próprio herói, confundido com Dante, na passagem do Inferno. Aqui, fala de dentro do ocaso, já sem vida. Para Dante, seu percurso é de perder-se e marchar para a morte. As duas sombras acompanham a viagem e o nostos, e se tornam referências centrais para todo o século XX. Assim, entende-se a figura de Ulisses como um tropo mítico-literário (cf. BOITANI, 2005), que propõe questões existenciais e históricas,

\footnotetext{
${ }^{1}$ Faço isso em diálogo incontornável com a noção de limiar benjaminiano, entendendo a poesia como lugar próprio desta condição. Se partirmos da discussão epistemológica em torno da diferença entre as noções de limiar (Schwelle) e limite/fronteira (Grenze), seguindo o rastro de Jeanne Marie Gagnebin, encontramos no conceito de "limiar" a tradução de experiências que designam ritos de passagem, como a morte, nascimento, casamento. Nesse eixo, seu sentido registra a noção de movimento, zona de mudança - temporal e espacial - fluxo e contrafluxo, permitindo a transição entre dois territórios, entre duas categorias (GAGNEBIN, p. 36), evocando também interregnos como os do desejo e das viagens.

${ }^{2}$ Segundo a reflexão de Gilles Deleuze e Félix Guattari à propósito da postura de Kafka diante da língua alemã. Cf. Kafka, para uma literatura menor, Lisboa, 2003, p.54.
} 
também presente na poesia de Ainda: em viagem, mais especificamente no poema "Atravessando". Como "discurso e imaginário da civilização ocidental", cujo sentido absorverá o viés filosófico, ético, político, mítico de cada tempo histórico, Ulisses converte-se em um NOME: uno, Ninguém, e cem mil. Mas, principalmente, está destinado a permanecer uma sombra e carregar esta designação desde sua trajetória inicial. A Odisseia foi, portanto, o germe de uma tradição literária cujos topoi da viagem e errância serão ressignificados inúmeras vezes. Isso nos interessa na medida em que carrega, em si, o peso do ser e de existir, e serve ao poeta como mote para refletir sobre o drama de estar no mundo, além de permitir que se lance o olhar para os traços que acompanham o viajante, até o século XXI.

Na poesia de Age, a viagem desdobra-se em camadas de sentido que traduzem o processo de travessia, o drama existencial e metafísico, a memória da infância e dos mortos, a reflexão sobre o tempo, a existência e seu desaparecimento, a experiência de exílio, e até mesmo o encontro amoroso. Dada a limitação de espaço, detenho-me apenas em dois poemas, ambos de seu mais recente livro - Ainda em viagem (2015). O primeiro, "Ele, o rico-de-sombras", realiza uma espécie de nekya pessoal, evocando um morto (o amigo Max Martins) na tentativa de tocar, com a poesia, a zona liminar entre o ser e o não-ser, encenada tipograficamente no poema (o que lhe confere alto teor dramático). "Ele, o rico-de-sombras,/que da ruína/de um sonho, um/ $\Psi /$ restante salvou/na folha nova,/açafrão e violeta/o perfume da letra/solitária". Em poemas como esse, depõe-se sobre o vazio e a ausência deixados pelo apagamento do ser, e a poesia converte-se em uma dramática tentativa de burlar o silêncio da desaparição, em um ritual de retorno à existência pelo poder de evocação que a palavra traz: "meu poder, meu poder/de trazer o morto/de novo/no ombro do poema", dirá ele num outro poema ao amigo desaparecido.

Aqui, Max Martins, morto em 9 de fevereiro de 2009, amigo-mor e poeta-eleito, aparece sob o jugo da morte, acolhendo-a dentro da noite escura e última, sob os auspícios de Safo. "Ele, dentro/de sua noite/sem a Lua e as Plêiades,/a hora parada,/atado a um leito/de hospital,/ sozinho." A solidão profunda, marcada pela hora parada, em que nada existe, é intensificada pela referência à poeta de Mitilene. A este homem, atado a um leito de hospital, são roubadas até a Lua e as Plêiades. Está sozinho, sem ninguém, o sinal da morte separando-o do mundo, como as palavras "solitária" e "sozinho" em destaque. Se, em outro poema ("No hotel"), onde Safo indiretamente 
também é evocada, pela lembrança do mesmo famoso fragmento a ela atribuído: "A lua já se pôs, as Plêiades também: é meia-/noite; a hora passa e eu,/deitada estou, sozinha”, se nele, o ardor da solidão amorosa no quarto de hotel leva à interrogação do quanto de ardor se pode doar no ermo do aposento vazio, e daí para a solidão originária e última do homem no mundo, em "Ele, o rico-de-sombras" trata-se do momento derradeiro de partida, da ausência de sentido.

O suspiro final, graficamente inserido no poema pelo colchete isolado em um único verso, convoca a presença do que se extingue, separa o mundo dos vivos e o "outro" mundo, a porta aberta, cruzados os limites intransponíveis, feito o caminho sem volta, de onde homem algum jamais retornou, ganhando forma visual pelo pontilhado. Ele, cara/a cara com/Daímon oloph, o funesto/[um deus que se lamenta]/ao lhe abrir a porta/[/................................/Ele, o/maior de todos/que assim se foi”. Cara a cara com o daímon - ser do entre-mundo, conexão entre vivos e mortos, como Odisseu - é conduzido ao domínio de Hades, de onde só sairá evocado pela poesia.

Para Dante, Ulisses transforma a morte em narração. Por isso, fala de dentro do inferno, já velho, perfazendo o discurso da travessia da maturidade à velhice. Transfigura o fim em palavras, diz o indizível, o vestígio, que não vem de fora, mas do homem, de dentro do túmulo. Ao passar as Colunas de Hércules, move-se para o Ocidente, virando a proa para a noite, rumo ao ocidente geográfico (oeste). Faz o percurso "por trás do sol”, "do mundo sem mais gente”, pela noite infinita. Dante abre o mito para a escuridão, onde começa a impossibilidade de retorno à casa. Ao passar as Colunas, a única luz a guiar a partir daquele momento é a luz das estrelas e da lua. (Cf. BOITANI, 2005, pp. 15-30). Por isso, retiradas a Lua e as Plêiades, a escuridão evocada no poema de Age é total e absoluta, anunciadora do naufrágio final.

A reflexão sobre a morte também é ensejada em poemas como "Blacknight" (também do último livro), que tem na composição da imagem da noite escura, que confere nome ao título, o cruzamento com outra imagem - a do cavaleiro negro (black knight). Atravessando o tempo, faz o percurso entre estar no mundo, sob as estrelas, e o retorno à terra, na Hora escura e última. "Noite" e "terra", imagens que concentram o elemento lírico, medeiam a travessia do início ao fim da vida, no poema. Operam também como símbolos da suspensão de tempo e espaço no momento da Hora marcada, quando o cavaleiro pode enfim soltar as rédeas dentro da noite escura e retornar à terra, culminando no neologismo "Desbelém", de alta carga emotiva. Aqui a imagem do desaparecimento da existência atua sobre a percepção de tempo e espaço, 
desnarrando essas categorias. O poema apresenta-se como uma meditação sobre o estar no mundo, vinculando considerações filosóficas sobre o "estar-aí" (o dasein heideggeriano) a observações sobre a inserção no tempo cronológico e na constituição linguística, isoladas por uma linha imaginária que separa a existência e seu apagamento.

Se em Dante, Ulisses representa o desejo de conhecer o estupor e atordoamento da alma diante do maravilhoso, esse desejo também estará condenado, apesar de mover o homem. Odisseu é herói do nostos, mas o que lega à modernidade é justamente o nãoretorno. O conhecimento do mundo (a que a figura de Odisseu também está associada) possui fronteiras demarcadas que coincidem com o limite do intransponível, que reenvia os homens para casa. Mas o retorno não apaga o vestígio da peregrinação ao Hades, porque é ela que "dá espessura à memória" (cf. BOITANI, 2005).

Assim, essa sombra paira sobre a poesia, sobretudo na modernidade, vinculada ao elemento de obscurecimento ou fechamento característicos do poema, e retorna nos eventos narrados por ela, porque para explorar essa via, há que se ter antes de tudo a vivência dos extremos, do abismo. Esse abrir-se para a ruína talvez seja uma das formas de expressão mais contundentes da obra poética de Age. Porque ela, a poesia, torna-se um transporte de resistência e adiamento do fim abissal, única garantia e consolo que a inevitável passagem do tempo traz ao homem. A viagem é refeita na narração e ganha as dimensões não só da travessia externa, em relação aos mortos que carrega em seus poemas, mas também interna, de autognose, ainda que o retorno para casa seja impossível e que Ulisses se torne outra coisa, Cada Um e Ninguém, Sereia (Kafka), um cão (Conrad), o antimito.

O poema “Atravessando" é o único a fazer referência direta à figura de Ulisses, e às Sereias, trazendo para o cotidiano a convivência com a morte, aceitando a sua participação diária na vida:

\author{
Atravessando \\ o último dia do ano, \\ tapada a concha \\ do ouvido, \\ atado a todos \\ os Novedefevereiros \\ dor- \\ avante:
}




serás
eu e eu
serei a
sirena
dizes,
assim ficamos
acordados.

Mais uma vez, um poema evocativo do Ano Novo. Trespassando essa divisa, perfazendo a passagem do vivo para o não-vivo e vice-versa, entre os mundos, como Odisseu, o sentimento lírico é dado por aquilo que prende emocionalmente o sujeito: o aniversário de falecimento do amigo, data de desaparecimento que retorna interminavelmente a cada novo ano, trazendo o morto à presença. Mas há um pacto, urdido na e pela palavra poética: ainda que dali em diante a dor seja reencenada a cada ano ("dor-/avante"), sempre futura, acompanhando o sujeito lírico vida afora, avança-se para frente, não para o passado. Mas o pacto, confirmado entre o "eu" e o "tu" do poema, onde este "tu" se ergue como uma alteridade, forma duplicada do "eu", desdobra-se, e o mito é alterado. O "acordo" - que é também "de acordo" com Ulisses, semelhante a ele - é ao mesmo tempo estar em concordância, selado o pacto, e estar desperto, pois assim não se morre, inebriado com o canto das Sereias. E os dois "eus", repetidos no mesmo verso, iniciam um jogo de espelhamento em que o morto fala de dentro da escuridão, exortando o vivo a assumir seu lugar, apresentado como uma espécie de super-ego do sujeito lírico, enquanto passa a assumir o lugar da sereia. Alternando-se em um jogo linguístico em que o tempo verbal interfere nas comutações entre as palavras (serás, serei a/sereia, sirena) - assumem-se como verso e reverso do mesmo, os dois poetas, Ulisses e as Sereias (sirenas) um e o mesmo, cada um e ninguém, seres-em-morte. A sirena (toque, campainha - de ambulância, de polícia, do mundo urbano, contemporâneo, maquínico, essa versão atual das cantoras arcaicas), atravessa o coração do cotidiano, relembra que é chegado o termo do mundo, o ocaso do ser, através da memória da data comemorativa, relembrando também que a poesia traz de volta o morto ao poema, emprestando-lhe a voz, mantendo-o vivo pelo canto.

A última viagem de Odisseu, portanto, é ultrapassar, transgredir. Deslocamento através do tempo, para frente e para trás; rumo ao ser e ao não-ser que, reencarnado na 
cultura brasileira, vai desembocar na utopia do deslugar, locus de contradição de uma identidade, de um território, ainda vigente nos dias de hoje. Para além do retorno e do que vem depois, não está o finito, nem o infinito, mas o transfinito (e a conexão aqui é com Haroldo de Campos), lembrará Boitani. Ao final, a figura de Ulisses atuará como desígnio de uma viagem que começa com a gênese da poesia, se desenvolve como ruptura e termina como naufrágio.

Penetrar no reino desconhecido do ser, do saber, da narrativa é deparar-se com esse vazio, seja pelo conhecimento do indivíduo e do mundo evocado no canto das sereias, ou pelo cruzamento das Colunas de Hércules, limite que homem algum jamais acessou, transpondo a fronteira ontológica que separa a existência e sua extinção. Seja na tentativa de apreensão do poético. De um lado, como procura do inexplicável e captura do invisível. De outro, na ideia de que a poesia é muitas vezes uma revelação. Ou seja, uma ponte entre o invisível e o aparente. Na descrição de Wallace Stevens dada por Piero Boitani: "a pheasant disappearing in the brush" - um faisão que desaparece no bosque, que some na penumbra, vivo, pronto a alçar voo e a fugir; e ao mesmo tempo, um faisão que desaparece sob o pincel, mancha, borrão de uma existência que se apaga sob a tinta. Limiar entre visibilidade e inacessibilidade.

Portanto, nesta jornada, ainda em curso e trespassada pelo cotidiano, pelas mazelas e prazeres do corpo e pela mais íntima e ancestral fala da reminiscência, o tempo se expande em espera. E a memória recupera, apenas em forma de rastro e resquícios, a recolha desses fragmentos de vida transfigurados pela linguagem. O mais importante: as palavras que executam esse retorno não operam o regresso de um todo, mas de resíduos, que se tornam experiências de resistência do vivo na execução de uma linguagem poética do inacabamento. Talvez aí resida seu caráter de obscuridade, característico da poesia moderna, e que se prolonga na contemporaneidade, porque condição de existência do próprio poema.

\section{REFERÊNCIAS}

ALIGHIERI, D. A divina comédia. São Paulo: Ed. 34, 1998.

ANDRADE, C. D. A rosa do povo. In: Poesia completa e prosa. Rio de Janeiro: Ed. Aguilar, 1973.

ÁVILA, A.. Carta a Age de Carvalho, $1^{\circ}$ agosto de 2003, pertencente ao acervo pessoal do poeta. 
BLANCHOT, M. A parte do fogo. Rio de Janeiro: Ed. Rocco, 1997.

BOITANI, P. A sombra de Ulisses. São Paulo: Ed. Perspectiva, 2005.

CARVALHO, A. Ainda: em viagem. Belém: Ed.ufpa, 2015.

Trans. Rio de Janeiro: 7Letras, 2010

Caveira 41. Rio de Janeiro: 7Letras, 2003.

GAGNEBIN, J. M. História e narração em Walter Benjamin. São Paulo: Ed. Perspectiva, 2004.

HOMERO. Odisseia. Trad.: Carlos Alberto Nunes. São Paulo: Ediouro, 1970. 